\title{
Novas luzes sobre a Segunda Sofística
}

New lights on the Second Sophistic

Pedro Zanetta Brener ${ }^{1}$

e-mail: brener.pedro@gmail.com orcid: http://orcid.org/0000-0001-7092-4039

Paulo Martins ${ }^{2}$

e-mail: paulomar@usp.br

orcid: http://orcid.org/0000-0002-2321-1033

DOI: http://dx.doi.org/10.25187/codex.v5i2.12281

\section{Resumo:}

O estudo do período conhecido como Segunda Sofística, assim denominado por Filóstrato, o Velho, tem crescido na academia. À medida que a retórica sofística é reabilitada nos estudos da filosofia e da literatura - movimento significativo na academia desde, pelo menos, os anos 60 -, a compreensão das práticas letradas dos primeiros séculos do Império Romano e de suas auctoritates vem sendo modificada, abandonando estigmas longamente perpetuados. Esse estudo visa a coligir aspectos mais relevantes da prática sofística no período, reunindo importantes contribuições a respeito, de modo a introduzir o leitor em um dos períodos mais profícuos da história romana através da abordagem minuciosa que lhe é dirigida modernamente.

Palavras-chave: retórica; Filóstrato, o Velho; segunda sofística; memória cultural

Abstract:

The study of the period known as the Second Sophistic, thus coined by Philostratus the Elder, has been swiftly rising in academia. As sophistic rhetoric is rehabilitated in the study of philosophy and literature a significant movement in academia since at least the 1960s - the comprehension of early-Roman Empire literary practices and its auctoritates is being modified, leaving behind long-lasting stigmas. This study aims at compiling the most relevant aspects of sophistic practice during the period, gathering the most important scholarly contributions to it, in order to introduce the reader into one of the most proficient epochs of Roman history through the approach contemporarily adopted to it.

Keywords: rhetoric; Philostratus the Elder; second sophistic; cultural memory

${ }^{1}$ Graduando de Letras (Grego e Português) da Universidade de São Paulo (Brasil); bolsista de Iniciação Científica da Fundação de Amparo à Pesquisa do Estado de São Paulo (FAPESP), sob a orientação do Prof. Dr. Paulo Martins.

2 Professor Livre-Docente do Departamento de Letras Clássicas e Vernáculas da Faculdade de Filosofia, Letras e Ciências Humanas da Universidade de São Paulo (Brasil); Pesquisador do Conselho Nacional de Desenvolvimento Científico e Tecnológico (CNPq); Visiting Professor no King's College London e Visiting Fellow na Yale University. 


\section{1) (3)}

\section{Segunda Sofística?}

O termo "Segunda Sofística", cunhado por Filóstrato, designa normalmente o período entre os séculos I e III d.C. ${ }^{3}$. O sofista classifica como "primeira" sofística a praticada em Atenas no século V a. C. por figuras como Górgias e Protágoras e, apesar de identificar o movimento de que faz parte com esta, não o faz a ponto de considerá-lo sua continuação. Apresentando-o independentemente, Filóstrato trata das diferenças entre a sofística praticada na Ática clássica e a praticada nos primeiros séculos d.C.: além do critério temporal, Filóstrato afirma que a primeira sofística se preocupava com a retórica filosófica, enquanto a segunda, com a retórica enquanto $\mathrm{tal}^{4}$.

Esse critério é, no entanto, tão vago quanto, no mínimo, tendencioso. Nas Vidas dos sofistas, Filóstrato procura apresentar a Segunda Sofística como uma "Renascença" da sofística clássica. O autor quer-nos fazer crer que a sofística é um fenômeno do início do Império, e que os sofistas então aparecem como líderes culturais, membros da elite política e intelectual do período ${ }^{5}$. Filóstrato apresenta como precursor dessa nova sofística Ésquines ${ }^{6}$, mas, por sua vez, curiosamente desconsidera os últimos dois séculos a.C. Contudo, a atividade retórica continuava agitada e prestigiosa em Roma, acendendo controvérsias entre aticismo e asianismo, assim como já era utilizado também o termo ooфıotńs a oradores excepcionais, ao menos na Grécia7. Assim bem atestam as obras de Cícero. O Bruto traça uma história da história da prática retórica nesses séculos e o Sobre o orador, apesar de tratar do que vem a ser o orador ideal, em certa medida, ocupa-se da crítica a certos oradores de seu tempo, operando as categorias dos três estilos: o simples, o médio e o sublime. Fato é que Cícero, portanto, opera os objetos que serão "negligenciados” por Filóstrato.

É certo que a alcunha de Segunda Sofística induz à confusão, visto que separa demasiadamente a produção retórica deste período e a retórica clássica ateniense. Além disso, trata-se a Segunda Sofística não apenas da oratória, mas pode ser compreendida como todo o

\footnotetext{
3 PERNOT, 2006, p. 30; WINTERBOTTOM, 2006, p. 74; SIRAGO, 1989, p. 39.

4 VS 481; ANDERSON, 1993, p. 16.

5 ANDERSON, 1993, p. 18; SIRAGO, 1989, p. 39; BOWERSOCK, 1969, p. 43.

6 VS 481.

7 ANDERSON, 1993, p. 18.
} 
movimento literário, cultural e social (e, por vezes, político) que se deu nesse período em torno de ṕńторєs, suas cidades e suas atividades no Império. Aquilo a que se chama Segunda Sofística não é o começo de algo novo, tampouco o resgate inusitado de algo que se perdera na história literária e retórica, mas é, na verdade, parte de um processo relativamente contínuo que desde Górgias e através do helenismo conduz, com alternativas de ação e reação, à época imperial ${ }^{8}$.

Podemos pensar, então, que a Segunda Sofística opera a memória cultural helênica em Roma, haja vista que recupera, de um lado, aspectos da formação cultural como o texto, os ritos e os monumentos de antanho; e, de outro, a comunicação institucional observada a partir da recitação, da prática e da observação. Nesse sentido, a memória cultural serve ao povo helênico em Roma como concretion of identity definida por Assman, já que as manifestações objetivas da Segunda Sofística são definidas por uma espécie de identificação daquilo que são os gregos em Roma9.

\section{Sofística na época imperial e passado helênico}

A relação entre a sofística ateniense do século $\mathrm{V}$ a. C. e a sofística dos primeiros séculos da nossa era é bastante complexa, e tomar a segunda simplesmente por ressurgimento da primeira não nos esclarece frente às dificuldades apresentadas pelo escasso testemunho a que temos acesso.

As letras do início do Império invocam um tradicionalismo em todas as suas manifestações, tendo como referências, além de Homero, sobretudo autores áticos dos séculos $\mathrm{V}$ e IV a. C., seja na historiografia embasada nos modelos de Heródoto e Tucídides, seja nas escolas filosóficas platônica, peripatética, pitagórica, estoica e cínica, ou ainda na oratória sofística baseada nos modelos de Protágoras, Górgias e Isócrates ${ }^{10}$. É ponto pacífico entre estudiosos que o mundo grego, no início do Império, visava seu passado com orgulho e nostalgia como reação à impotência política do presente ${ }^{11}$. É importante questionar, entretanto, como alerta Bowie (1970, p. 6), o porquê da eleição desse período como referência, bem como sua extensão.

Parece-nos que a Segunda Sofística, ainda que "sofra" de uma nostalgia indene em relação ao passado "glorioso dos atenienses" com a devida vênia a Plutarco, não se furta a criticar posições ortodoxas da filosofia platônica no que concerne à precariedade das imagens, da poesia e, consequentemente, da imitação, de sorte que o próprio Filóstrato no proêmio aos Eikones

\footnotetext{
8 LESKY, 1971, p. 487; ANDERSON, 1993, p. 46.

9 ASSMAN, 1995, p. 128-30.

10 PERNOT, 2006, pp. 30 e 33; BOWIE, 1970, p. 20; LESKY, 1971, p. 487.

${ }^{11}$ ANDERSON, 1993, p. 101; BOWIE, 1970, p. 26; BRUNT, 1994, p. 36 - com ressalvas; GOLDHILL, 2001 , p. 8.
} 
propõe a apologia da mimese, da arte plástica e pictórica e da poesia, dizendo que quem não as respeita, erra contra a sabedoria e contra a verdade (á $\delta 1$ kعĩ ora isto não é uma apologia das concepções de Platão no livro 10 d'A República ${ }^{12}$ e no Sofista ${ }^{13}$.

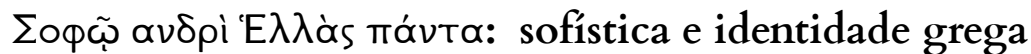

Traçar os fundamentos da identidade grega não é tarefa simples, tampouco o objetivo deste estudo. Mais relevante, parece-nos, é analisar que aspectos dessa identidade são relevantes para o entendimento da sofística imperial, e de quais ela se vale.

O helenismo foi sempre definido em oposição aos não-gregos, os ßápßapor. A identidade desses sofistas, sob o Império Romano, revela-se, no entanto, um complexo tanto mais elaborado de relações, inimizades e amizades poético-retóricas do que o simples "helenismo"14. Os laços desses autores com suas origens são uma quimera, compostos tanto pelo fundo helênico quanto pelas cidades em que nasceram e que adotaram, e que talvez constituam o foco central de sua memória e lealdade15.

Para além dessa questão, encontramos uma ainda mais complicada: a auto-representação e a recepção do sofista. A cultura grega é, tanto para Filóstrato quanto para Luciano, por exemplo, parte fundamental dos seus projetos intelectual e social ${ }^{16}$, mas sua representação é variada. A identidade grega, como quer que fosse definida no passado, durante o Império não é definida pela genealogia ou pelo local de nascença, mas pelos hábitos, pela língua, pelas referências e pela aparência; a identidade grega é um estilo socialmente construído, a adequação a conceitos valorizados em conjunto (dicção, aparência, inteligência, civilidade, masculinidade) ${ }^{17}$.

Desse modo, podemos tratar de uma identidade cultural grega como um posicionamento social, um modo de relação e de representação pública de si $^{18}$. Os sofistas da época imperial valiam-se largamente de gestos, indumentária e penteados para causar efeito na plateia19. $\mathrm{O}$ cuidado com a imagem que passavam ao público era essencial, e seus resultados variavam dos

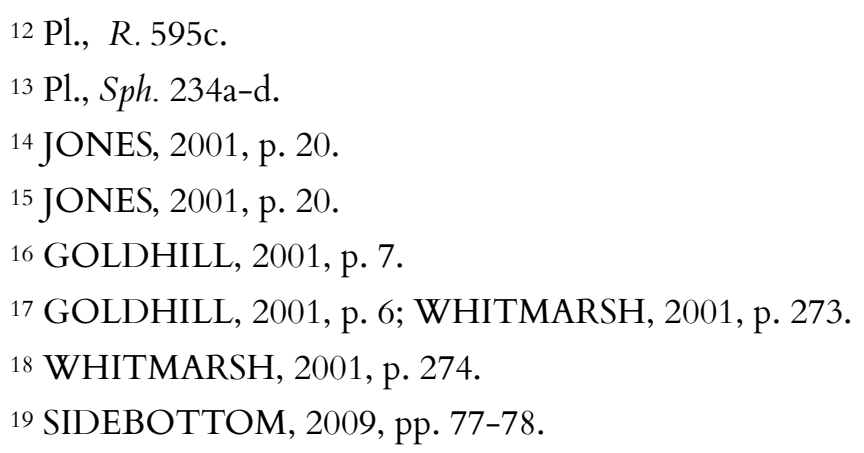


mais profícuos aos mais desastrosos ${ }^{20}$. Do mesmo modo que seu sotaque influenciava sua recepção ${ }^{21}$, assim também o fazia sua apresentação ao público em todos os seus detalhes: depilação, vestimenta, transpiração e postura ${ }^{22}$.

A adoção de uma elocução mais ou menos aticizante, de construções retóricas mais ou menos ornamentais, mais ritmadas ou mais "conservadoras", fazia parte desse complexo de símbolos disponíveis à construção da imagem pública e discursiva do sofista. A cada detalhe que compõe a persona retórica do sofista vêm atrelados outros tantos, que em sua organização compõem uma identidade grega, mas também romana ${ }^{23}$, ática, mas não exclusivamente ${ }^{24}$, que equilibra ideais contemporâneos e antigos ${ }^{25}$.

O simbolismo da identidade grega que se vai formando entre os sofistas dos primeiros séculos de nossa era não é, portanto, ligado fundamentalmente à terra pátria ou à genealogia familiar, mas à cuidadosa construção e representação de si. Essa caracterização é, claro, definida em oposição a outros estatutos simbólicos, e traz consigo uma série de valores associados direta ou indiretamente - urbano, civilizado, culto, refinado, eloquente - que o sofista manipula conscientemente, com resultados mais ou menos positivos ${ }^{26}$. O capital simbólico investido pela elite grega na figura do sofista (assim como na do filósofo) era suficiente para que operasse, em certo nível, com o poder romano ${ }^{27}$.

\section{Sofística e Taı́fía}

Discussões sobre a posição que ocupava a educação na cultura e na sociedade helênicas são inúmeras, e sua ligação com o fenômeno da chamada Segunda Sofística é muito estudada.

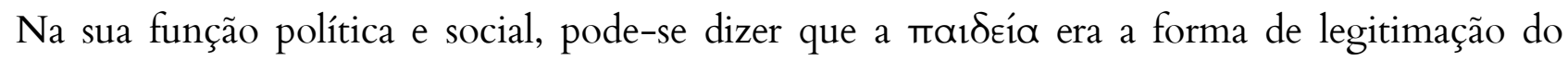
poder das elites das cidades gregas par excellence ${ }^{28}$, e a classe dominante delegava a legitimação de seu poder coletivo à figura do sofista, culto, eloquente e sábio, que se apresentava publicamente como pars pro toto, num jogo de representações metonímicas.

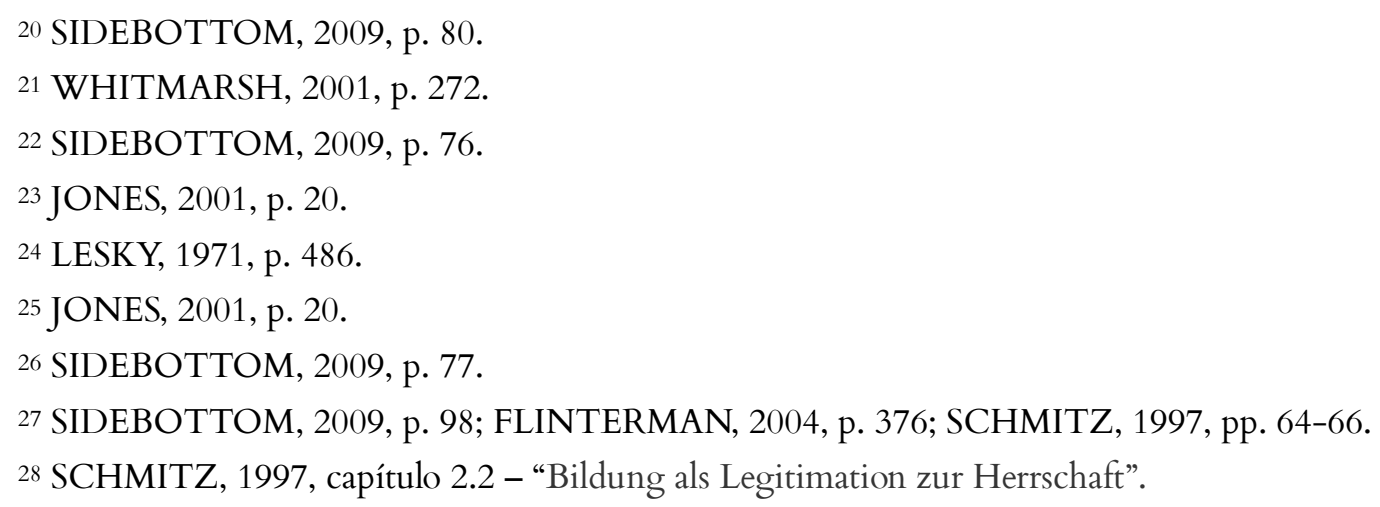


Em relação à sua função sobre a construção do sofista, sua identidade, sua recepção e suas relações, é importante notar que a educação da elite grega no Império Romano incluía - e há quem afirme que era baseada sobre - a retórica ${ }^{29}$. Sofistas eram, além de oradores públicos e, por vezes, forenses, professores de retórica e oratória ${ }^{30}$.

$\mathrm{O}$ ensino de retórica oferecido às elites era baseado em exercícios conhecidos como

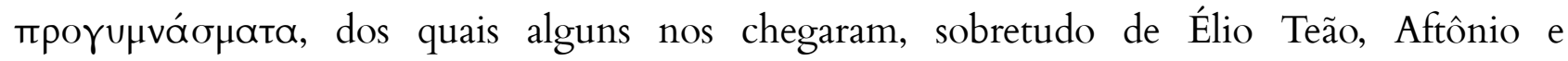
Hermógenes. Esses, que tratam de diversas figuras retóricas, são compostos por exercícios de narrativa, écfrase, prosopopeia, тómos, encômio, etc ${ }^{31}$. Naturalmente, não é difícil imaginar que os professores realizassem eles mesmos os exercícios, em demonstração aos alunos ${ }^{32}$. Além disso, porém, cada um desses exercícios adotava um cânone de referências. Para a écfrase, por exemplo, o modelo por excelência era a descrição do escudo de Aquiles, na Ilíada, bem como passagens de Heródoto e de Tucídides o eram para a narrativa ${ }^{33}$.

Para quase todo o ensino da retórica - e não apenas da retórica -, Homero era o grande modelo. Em cada caso, porém, os outros modelos adotados costumavam fazer parte do cânone literário da Atenas nos séculos V e IV a. C. A elite grega do Império Romano era composta de conservadores, e quanto aos modelos que pautavam sua educação não teriam, portanto, posicionamento diferente ${ }^{34}$; e, assim, inseriam-se linguística, estilística e tematicamente na série literária da Atenas democrática ${ }^{35}$.

Todo o arsenal de referências disponível a esses homens remontava à Grécia, sobretudo à Ática do século V a. C. ${ }^{36}$. A imitação dos clássicos atenienses era encorajada, assim como o grego ático assumiu uma posição de língua franca entre as elites educadas do Império, tanto a seu oeste quanto, também, a seu leste ${ }^{37}$. A postura dos filósofos imitava, em certa medida, o paradigma dado pelo Sócrates de Platão. Independentemente da escola que seguissem no Império, seu posicionamento era dialógico, e sua atividade, crítica ${ }^{38}$. Do mesmo modo, os sofistas do Império

\footnotetext{
29 SIDEBOTTOM, 2009, p. 79; GOLDHILL, 2001, p. 13.

30 BOWIE, 1970, p. 8; BRUNT, 1994, p. 29.

31 KENNEDY, 2003; MARTINS, 2017.

32 WINTERBOTTOM, 2006, p. 79.

33 KENNEDY, 2003, pp. 46 e 75; MARTINS, 2016, p. 165.

34 PERNOT, 2006, p. 33.

35 WHITMARSH, 2001, p. 271.

36 PERNOT, 2006, p. 33.

37 WHITMARSH, 2001, p. 272.

38 SIDEBOTTOM, 2009, p. 73.
} 
imitavam os modelos estabelecidos por Górgias, Protágoras e Ésquines, por exemplo. O mesmo ocorria na historiografia ${ }^{39}$ e nas artes plásticas ${ }^{40}$.

Essa tendência, especialmente na retórica e na filosofia, pode ser compreendida através da formação dos sofistas. Esses homens eram educados com referências e modelos da Atenas democrática, e viviam em meio que valorizava fortemente os ideais atrelados a esse período. Completamente imersos na cultura ateniense dos séculos V e IV a. C., os até então estudantes tornavam-se oradores e, por conseguinte, professores de retórica e oratória, mantendo em seus ensinamentos os modelos que lhes foram transmitidos.

Por outro lado, contudo, a auto-definição da elite grega no presente do Império Romano envolve tanto a apropriação do passado da Atenas democrática, quanto a transcendência de seus paradigmas; para o indivíduo educado de então, a gloriosa época ateniense era, ao mesmo tempo, familiar e estranha ${ }^{41}$. Filóstrato identifica diferenças entre a primeira e a Segunda Sofística, e o mesmo ocorre na filosofia e nas artes plásticas e pictóricas - assim como mudam os valores sociais, bem como as suas representações individuais e culturais, também mudam as manifestações artísticas e intelectuais, apoiadas sobre e transcendendo as suas referências atenienses.

\section{Aticismo e asianismo ${ }^{42}$}

A distinção do asianismo ao aticismo começou, expressamente, em cerca de 50 a. C., mobilizando questões não só linguísticas e estilísticas, mas também ideológicas e de identidade letrada. Naturalmente, o que se considerava asianismo ou aticismo mudou com o passar dos séculos, até chegar à diferenciação que se faz nos primeiros séculos $\mathrm{d}$. C.

Em linhas gerais, o aticismo é associado a um estilo austero e sem adornos de composição ${ }^{43}$, que utiliza somente o dialeto grego ático, estabelecido como padrão culto durante o período chamado de Segunda Sofística. A linguagem é, portanto, arcaizante, cristalizada por autores canônicos. Do mesmo modo, a elocução tomada por fundamentalmente ática é uma construção que não se verifica na prática.

\footnotetext{
39 BOWIE, 1970, p. 30.

40 BOWIE, 1970, p. 37.

41 WHITMARSH, 2001, p. 273; ANDERSON, 1993, p. 238.

42 Essa seção é baseada largamente sobre WILAMOWITZ-MÖLLENDORFF, 1900, pp. 533 e ss. Desse modo, restringir-nos-emos a apresentar apenas as referências a outras fontes bibliográficas.

43 COLVIN, 2006, p. 67.
} 
Já o asianismo, por outro lado, é considerado um estilo demasiadamente ornamentado, idiossincrático no uso vocabular e dialetal e inclinado a exageros de composição, uma corrupta eloquentia ${ }^{44}$ É importante notar que, apesar de ser relacionado o nome "asianismo" aos territórios a leste do Mediterrâneo por conta de sua associação à corrupção de valores clássicos e por serem tomados por bárbaros e afeminados, as alcunhas "aticismo" e “asianismo" não se referem a diferenças geográficas, mas a estilos distintos que podiam ser adotados por oradores nativos de qualquer região do Império.

Os sofistas e demais intelectuais gregos do início do Império voltam-se para o aticismo como mais um elemento da sua construção simbólica. Por conta do ensino das elites ${ }^{45}$, baseado na imitação dos clássicos, o grego ático tornou-se o dialeto padrão dos homens educados. No entanto, a dicção aticizante não é muito além de cobertura externa, que rende à sofística um ar de classicismo, seu prestígio e sua imagem ${ }^{46}$ - percebe-se que a filiação ao aticismo serve a fins sociais e políticos.

Se, por um lado, o conhecimento do grego ático falado na Atenas democrática era fundamental ao sofista, que se atinha às suas expressões e formulações como sinal de erudição, por outro, o orador era cirúrgico no tratamento do ritmo de suas frases, da cadência e da sonoridade de seu discurso, e adornava-o cuidadosamente em termos retóricos ${ }^{47}$ - assim como o fazia Cícero, cujos discursos eram criticados por demasiado asianismo. A aridez da dicção ática não servia bem aos propósitos da retórica dos sofistas do Império, que eram tão destros quanto exibicionistas; a musicalidade, a entonação e a fluidez do discurso lhes eram fundamentais para que causassem efeito na plateia, e disso o aticismo não os provia.

Em suma, não há verdadeiramente uma oposição ao asianismo pela sofística do período imperial - embora sofistas criticassem uns aos outros sob esse pretexto -, e tampouco há sua adesão completa ao aticismo, mas o que se verifica é a incorporação de traços tanto de um estilo quanto de outro, visando a propósitos sociais e retóricos bem definidos ${ }^{48}$. O ideal da pureza puritas - ática afirmou-se na expressão linguística - assim como tantos outros, em outros campos $^{49}$-, e sua adoção pelos sofistas não foi irrestrita, tampouco casual. Do mesmo modo, o

\footnotetext{
44 SIRAGO, 1989, p. 47; ver Petr. 2.7 e Tac., Dial. 34.4.

45 SIRAGO, 1989, p. 44.

46 SIRAGO, 1989, p. 48.

47 SIRAGO, 1989, p. 52.

48 SIRAGO, 1989, p. 54.

49 SIRAGO, 1989, p. 64.
} 
asianismo manteve-se sob a superfície do discurso ${ }^{50}$, permitindo, certamente, o que dá a esses textos parte de seu sabor e, decerto, o que lhes rendia parte de sua eficácia.

\section{Sofistas e filósofos}

As duas principais funções intelectuais no Império Romano eram as de sofista e de filósofo, e não eram mutuamente excludentes; podia-se ser um filósofo sofístico ou um sofista filosófico ${ }^{51}$. O critério para a aproximação de um filósofo da sofística era, sobretudo, a eloquência ${ }^{52}$, mas outros parâmetros entram em cena quando se consideram os papéis políticos e simbólicos assumidos por um e por outro53.

Oriundos da elite e educados de maneira similar, sofistas e filósofos realizavam, na sociedade, funções semelhantes, mas nem sempre idênticas ${ }^{54}$. Segundo Élio Aristides, ao sofista cabia adornar festivais, honrar os deuses, aconselhar e confortar cidadãos, acalmar desacordos cívicos e educar os jovens, funções que não cabiam aos filósofos ${ }^{55}$. Já os filósofos tinham um papel mais questionador, de aconselhar e criticar através do diálogo, não se dedicando à oratória pública, exercício fundamentalmente sofístico56.

Quanto à postura frente ao poder político, sofistas e oradores primariamente faziam pedidos e elogiavam, e através do elogio proviam o imperador e demais políticos de modelos a serem seguidos, enquanto os filósofos, por sua vez, advertiam ${ }^{57}$. A franqueza filosófica, a

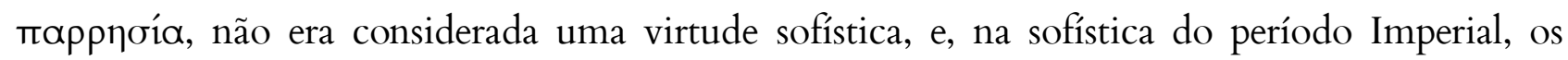
oradores raramente tomavam para si o papel de admoestadores ${ }^{58}$. Enquanto os filósofos manifestavam-se de acordo com uma certa conduta, a sofística funcionava como um meio para a construção e expressão da identidade da elite grega. Para cumprir essa função, era necessário que a oratória sofística se apresentasse como totalmente autônoma ${ }^{59}$.

\footnotetext{
50 LESKY, 1971, pp. 486-7.

51 SIDEBOTTOM, 2009, p. 69.

52 WINTERBOTTOM, 2006, p. 83; SIDEBOTTOM, 2009, p. 69.

53 Para mais informações sobre os papéis assumidos pelos sofistas na política imperial, ver adiante.

54 SIDEBOTTOM, 2009, p. 69.

55 SIDEBOTTOM, 2009, p. 72.

56 SIDEBOTTOM, 2009, p. 73.

57 RAWSON, 1989, p. 253; BOWIE, 2008, p. 1; SIRAGO, 1989, p. 23.

58 FLINTERMAN, 2004, p. 376.

59 FLINTERMAN, 2004, p. 376.
} 
A diferença entre a postura adotada pelos filósofos e pelos sofistas diante do poder político, evidentemente, acarretava diferenças no tratamento que recebiam por parte da alta classe política. Enquanto sob Adriano ambos receberam ampla imunidade, logo a situação mudou e tornou-se evidente a distância entre ambos perante o poder romano ${ }^{60}$ : Antonino Pio instituiu limites às concessões que Adriano fizera aos oradores e retirou completamente a imunidade concedida aos filósofos ${ }^{61}$.

Se, por um lado, a classe social e a formação dos filósofos e dos sofistas era muito semelhante, por outro, a apresentação de cada papel dava-se por uma rede de símbolos conscientemente contrastantes uns com os outros ${ }^{62}$. De maneira saussuriana, pode-se dizer que a

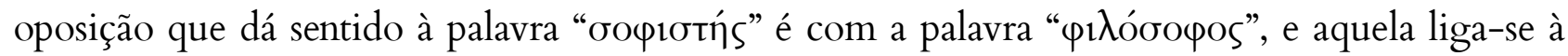

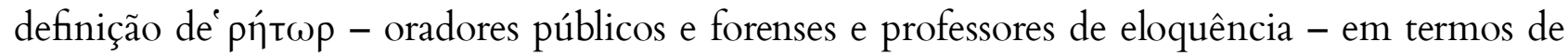
qualidade: um sofista é um ṕ́

Enquanto era possível afirmar que um sofista fosse filosófico, fosse pelos temas que abordava ou pela sua dicção, e que um filósofo era sofístico, pela sua eloquência, mais frequentemente, em tom derrogatório, não era possível afirmar-se sofista e filósofo simultaneamente, pois eram definidos em oposição mútua, simbolicamente excludentes um ao outro tanto em afirmações características, palavras, quanto em aparência, gestos e comportamento, ações públicas ${ }^{64}$.

Os filósofos vestiam-se sobriamente, quase como mendigos, deixavam crescer a barba e, a depender da escola que seguiam, os cabelos. Não recebiam presentes, não buscavam deleitar a plateia, não se gabavam de sua sabedoria ou de sua destreza com as palavras, mas reivindicavam sua liberdade de fala. A definição da aparência e do comportamento do filósofo era tão carregada que eram facilmente reconhecidos puramente pelo seu simbolismo exterior, a ponto de serem julgados como filósofos todo tipo de gente que não o era, sendo difícil divisar entre "falsos filósofos" e filósofos de fato65.

Os sofistas, por sua vez, firmavam sua apresentação simbólica de modo completamente distinto. Como afirma Filóstrato ${ }^{66}$, pendiam os sofistas à arrogância, garantindo seu

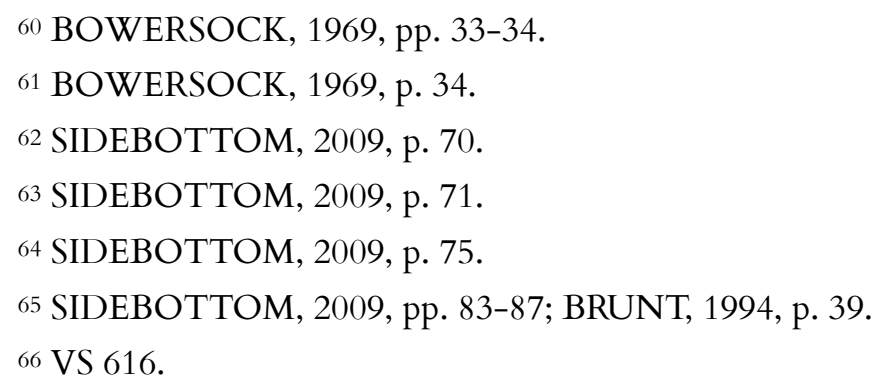


conhecimento, sua habilidade com as palavras e sua capacidade de fornecer educação verdadeira $^{67}$. Esses oradores tinham na plateia um importante espelho refletindo o efeito e a qualidade de seu trabalho, eram muito bem pagos e cuidavam imensamente de sua indumentária, entonação, atuação e aparência, já que todos esses fatores compunham sua actio pública e retórica ${ }^{68}$.

A diferença entre a construção simbólica de um e de outro papel é bem exemplificada pela trajetória de Arístocles de Pérgamo, contada por Filóstrato69. Arístocles era um filósofo peripatético e tornou-se um sofista. Nesse percurso, deixou de ser descuidado com sua aparência, desleixado e pobre em suas roupas, e passou a ser exigente; descartou seus modos descuidados e permitiu que entrassem em sua casa os prazeres da lira, da flauta e do canto.

Podem ser identificados claramente dois padrões opostos. Enquanto o sofista encarna os ideais urbanos, refinados e civilizados, o filósofo ocupa a posição de rústico, descuidado e livre, quase teimoso, retomando os ideais do herói homérico. Definidos por contraste, o status simbólico do filósofo muda junto com o do sofista, no sentido oposto, assim como, paradoxalmente, a ascensão de um leva à do outro ${ }^{70}$.

Como representantes simbólicos do rural e do urbano e da $\pi \alpha 1 \delta$ eía e do passado grego, comuns à elite social grega, filósofos e sofistas ultrapassavam os limites de qualquer cidade, podendo assistir numa qualquer indistintamente. Por um lado, tanto um filósofo como um sofista podiam aconselhar uma cidade que não fosse a sua sob o argumento de sua imparcialidade. Por outro lado, enquanto um sofista aconselhando uma cidade que não fosse a sua seria ainda um representante interior do ideal da vida urbana, um filósofo dirigindo-se à sua própria cidade, portanto falando do seu interior, permaneceria um representante do ideal de fora, vendo-a com olhos externos $^{71}$. Nas figuras do sofista e do filósofo, os gregos criaram papéis simbólicos poderosos para além da pólis ${ }^{72}$.

\footnotetext{
67 VS 535, 563, 617.

68 SIDEBOTTOM, 2009, pp. 77-80.

69 VS 567.

70 SIDEBOTTOM, 2009, pp. 94-97.

71 WHITMARSH, 2001, p. 282: “Inverting a well-known pun, Musonius tells us that exile 'strengthens' (errhosen, 44.3) its victims: rhome ('strength') is thus generated not by Rhome (Rome), but distance from it. Once again, the philosopher's exceptional status is constructed through a literary trope of segregation and distance, and expressed as a form of power which cannot be accessed through conventional civic hierarchies".

72 SIDEBOTTOM, 2009, p. 98.
} 


\section{Sofistas e a política imperial}

Os sofistas adquiriam grande fama nas suas cidades e acabavam por atrair os olhos do poder político romano. Sua fortuna, inteligência e patriotismo, expressos através de serviços públicos e benfeitorias, contribuíam largamente para a prosperidade de suas cidades e tornavamnos peças importantes na administração local, que era tão crucial para o bom funcionamento do Império Romano ${ }^{73}$.

Nos dois séculos anteriores ao período chamado de Segunda Sofística, a atividade dos homens de letras incluía regularmente serviços em embaixadas de oficiais e aristocratas romanos, e, por vezes, conselheiros do leste podiam ser reconhecidos na entourage de generais e imperadores $^{74}$. Já existia, nessa época, o embrião do movimento da Segunda Sofística, e, à medida que o Império se tornava cada vez mais uma unidade greco-romana, o papel desempenhado pelos litterati do leste crescia e consolidava-se ${ }^{75}$.

Sofistas encontravam-se em posição favorecida para ganhar os ouvidos e a simpatia de imperadores e detinham o poder de atrair e propiciar melhorias às suas cidades ${ }^{76}$. Além disso, por conta de sua proeminência, muitos acabavam por ocupar cargos públicos, tanto nas cadeiras de retórica e de grego em Atenas ou Roma, como em outras posições - geralmente ligadas às letras ou à área legal, naturalmente próxima aos sofistas devido à sua atividade forense -, como $a b$ epistulis (graecis), aduocati fisci, e mesmo embaixadores e cônsules ${ }^{77}$. A unidade do Império Romano permitiu que os oradores atingissem prestígio "interprovincial”, associando-se oficialmente ou não à liderança da aristocracia romana ${ }^{78}$.

De maneira mais ampla, para além das suas cidades e das concessões individuais, os sofistas ainda gozavam de privilégios na política do Império. Adriano, por exemplo, concedeu aos $p$ ṕtopes ampla imunidade e determinou que não fossem obrigados a servir contra sua vontade como juízes, embaixadores ou soldados ${ }^{79}$. Antonino Pio restringiu as concessões de

\footnotetext{
73 BOWERSOCK, 1969, p. 43.

${ }^{74}$ BOWERSOCK, 1969, p. 43.

75 BOWERSOCK, 1969, p. 44.

76 BOWERSOCK, 1969, p. 46.

77 BOWERSOCK, 1969, pp. 50-58.

78 BOWERSOCK, 1969, p. 58.

79 BOWERSOCK, 1969, p. 33.
} 
Adriano a uma quantidade limitada de oradores para cada cidade, a depender do seu tamanho ${ }^{80}$, mas ainda ocupavam posição prestigiosa.

Realizando diversas benfeitorias e atraindo ricos de todos os cantos do Império, os sofistas são uma expressão palpável da união entre as letras e a influência política e econômica tão característica do período conhecido como Segunda Sofística ${ }^{81}$. Sua importância era dupla: podiam ao mesmo tempo prover suas cidades de recursos e assegurá-los a elas através de sua influência 82 .

\section{Sofistas e suas cidades}

A sofística cresceu no Império Romano, nos primeiros séculos da nossa era, para além de Roma, em torno de cidades como Atenas, Éfeso, Esmirna, Pérgamo e Gadara, e seu ressurgimento foi parte importante do prestígio e da relevância econômica que essas cidades adquiriram durante o Império ${ }^{83}$.

Se, por um lado, só foi possível o florescimento da sofística nessas cidades devido ao crescimento econômico que já conquistavam, se foi o bem estar econômico das cidades asiáticas que facilitou o novo movimento intelectual, criou o gosto dos novos mestres, atraiu discípulos e indicou um caminho ${ }^{84}$, por outro, não se deve afirmar que a sofística, na época imperial, tenha um caráter citadino. A consolidação da sofística não se deve a uma razão particular de cidade ou província, mas porque tocava a toda a cultura imperial - a cultura retórica é um fenômeno universal no Império ${ }^{85}$, o que se ilustra pelas frequentes viagens dos sofistas a todas as suas partes.

A relação do sofista com a sua cidade, fosse ela sua cidade natal ou adotada por ele, era de patriotismo, talvez mais do que o era sua relação com a própria Hélade ${ }^{86}$. A lealdade do orador, em termos de benfeitorias, investimentos e pedidos ao poder político romano, era voltada, sobretudo, à sua cidade, e a geografia exercia um papel metafórico na construção da identidade ${ }^{87}$.

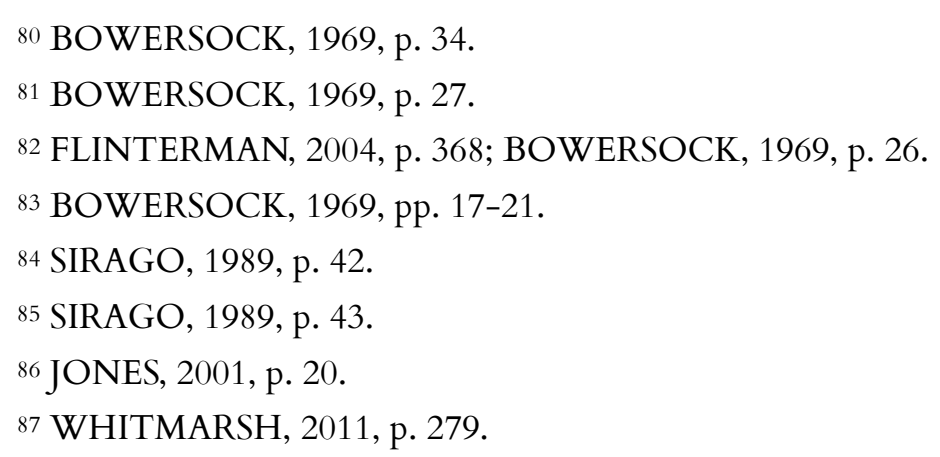


Por conta das exigências da carreira de sofista, a maior parte de seus representantes vinha de famílias notáveis, aristocratas locais que podiam dispor dos custos necessários para sua formação - instrução, viagens, etc. ${ }^{88}$. Muitas vezes, o métier permanecia por gerações na família, como nos casos de Filóstrato e Polemo ${ }^{89}$, e muitos tinham descendentes ou familiares em cargos públicos $^{90}$.

Devido à riqueza e à projeção que tinham, os sofistas podiam fazer muito pelas suas cidades em termos de infraestrutura, e faziam-no em larga escala1 ${ }^{91} \mathrm{Na}$ sua cidade ou província, natal ou adotada, era esperado do sofista que realizasse benfeitorias e serviços para além da sua simples presença ${ }^{92}$, e, desse modo, acabavam por enriquecer e tornar famosas suas cidades no Império93, à medida que enriqueciam e adquiriam fama eles mesmos.

\section{Conclusão: noções básicas e reavaliações}

É importante perceber que o movimento chamado por Filóstrato de Segunda Sofística não é, absolutamente, uma invenção dos primeiros séculos d.C. Como exposto na seção 1, a oratória não deixou de ser exercida entre os séculos V e IV a.C. e o I d.C., mas a decisão de Filóstrato de deixar de lado ao menos dois séculos de atividade retórica é programática e serve ao seu propósito historiográfico, retórico e sócio-político.

Não há, na verdade, um programa literário partilhado pelos autores citados por Filóstrato, tampouco uma relação tão específica entre a primeira e a Segunda Sofística. Entretanto, o termo "Segunda Sofística" nos concede benefícios: enfatiza a importância do treinamento retórico e as recompensas do sucesso retórico na sociedade imperial, além de reforçar a constante referência à tradição grega clássica, recorrente nos diversos gêneros praticados durante o período ${ }^{94}$.

Além disso, para que se possa compreender melhor a relação entre esse período e a Atenas dos séculos V e IV a. C., é necessário estudar a construção da identidade grega como individual e como manifestação pública. Entender as forças que atuam nesse processo (caminho que começou a ser trilhado por Ewen Bowie em 1970 e que só foi retomado décadas depois) é o

\footnotetext{
88 BOWERSOCK, 1969, p. 21.

89 BOWERSOCK, 1969, p. 24.

90 BOWERSOCK, 1969, p. 43.

91 BOWERSOCK, 1969, p. 17.

92 BOWERSOCK, 1969, p. 26.

93 BOWERSOCK, 1969, p. 29.

94 GOLDHILL, 2001, p. 14.
} 
primeiro passo para que entendamos exatamente o papel que exercem essas referências nas manifestações literárias e culturais do Império Romano.

De que modo se apresentam esses homens, isto é, como são vistos e como se veem, é parte da função política e social que exercem, e compreendê-lo talvez seja a única maneira de compreender sua atividade e importância, seja através da sua relação com a $\pi \alpha 1 \delta$ cía, através do estudo do seu estilo ou comparando-os às outras figuras fundamentais da produção intelectual da época, ou mesmo questionando diretamente suas condições materiais e sua relação com a política. A construção simbólica da identidade grega e da figura do sofista em todos os seus detalhes levam os expoentes dessa oratória à mais alta relevância na história romana e constituem no mínimo um empate, ao menos simbólico, entre as elites gregas e o poder político romano, assim como os textos que nos chegaram lhes rendem relevância correspondente na literatura e na retórica gregas.

\section{Referências Bibliográficas}

\section{Antiga:}

FILÓSTRATO. The life of Apollonius of Tyana. Cambridge, Mass: Harvard University Press (The Loeb Classical Library), 1912. Classical Library), 1952. . Lives of the sophists. Cambridge, Mass: Harvard University Press (The Loeb . Imagines. Cambridge, Mass: Harvard University Press (The Loeb Classical Library), 2000.

PLATÃO. Theaetetus. In. Plato, vol. VII. Cambridge, Mass: Harvard University Press (The Loeb Classical Library), 1921.

. O sofista. Trad. Carlos Alberto Nunes. Fonte digital: Site "O Dialético". Disponível em www.odialetico.hpg.ig.br. Versão para e-book eBooksBrasil.com, 2003.

. Górgias. Trad. Daniel R. N. Lopes. São Paulo: Perspectiva, 2014.

\section{Moderna:}

ANDERSON, G. "The pepaideumenos in action: Sophists and their outlook in the Early Roman Empire”. Aufstieg und Niedergang der römischen Welt, v. 33, n. 1, pp. 79-208. Berlin: Walter de Gruyter, 1989.

Routledge, 1993.

The Second Sophistic: a cultural phenomenon in the Roman Empire. Londres: 
ASSMANN, J. "Collective memory and cultural identity”. Translated by John Czaplicka in: New German Critique 65: pp. 125-133.

BORG, B. E. "Rhetoric and art in third-century AD Rome" in: ELSNER, J., MEYER, M. (ed.) Art and rhetoric in Roman culture. Cambridge: Cambridge University Press, 2014.

"Glamorous intellectuals: Portraits of pepaideumenoi in the second and third centuries AD”. In: GOLDHILL, S. (ed.) Being Greek under Rome: cultural identity, the Second Sophistic and the development of Empire. Cambridge: Cambridge University Press, 2001.

BOURDIEU, P. Esquisse d'une théorie de la pratique. Paris: Droz, 1972.

. Langage et pouvoir symbolique. Paris: Points, 1991.

BOWERSOCK, G. W. Greek sophists in the Roman Empire. Oxford: Oxford University Press, 1969.

BOWIE, E. L. "Greeks and their past in the Second Sophistic". Past Present, v. 46, n. 1, pp. 3-41, 1970.

- "Greek sophists and Greek poetry in the Second Sophistic". Aufstieg und Niedergang der römischen Welt, v. 33, n. 1, pp. 209-258. Berlin: Walter de Gruyter, 1989.

. "Philostratus: the life of a sophist". In: BOWIE, E. L., ELSNER, J. (ed.) Philostratus. Cambridge: Cambridge University Press, 2009.

- "Quid Roma Athenis? How far did Imperial Greek Sophists or Philosophers debate the Legitimacy of Roman Power?”. In: URSO, G. (ed.) Ordine e sovversione nel mondo greco e romano: atti del convegno Internazionale, Cividale del Friuli, 25-27 Settembre, 2008. ETS. 2009.

. "The geography of the Second Sophistic: Cultural variations". In: GOLDHILL, S. (ed.) Being Greek under Rome: Cultural identity, the Second Sophistic and the development of Empire. Cambridge: Cambridge University Press, 2001.

BRANCACCI, A. "Seconde Sophistique, historiographie et philosophie (Philostrate, Eunape, Synésios)”. In: CASSIN, B. (org.) Le plaisir de parler. Paris: Les Éditions de Minuit, 1986.

BRUNT, P. A. "The bubble of the Second Sophistic". Bulletin of the Institute of Classical Studies, v. 39, pp. 25-52, 1994.

CASERTANO, G. Sofista. Napoli: Alfredo Guida Editore, 2004.

COLVIN, S. C. “Atticist-Asianist controversy". In: SLOANE, T. O. (ed.) Encyclopedia of rhetoric. Oxford: Oxford University Press, 2006.

FLINTERMAN, J. J. "Sophists and emperors: a reconnaissance of sophistic attitudes". In: BORG, B. E. (ed.) Paideia: The world of the Second Sophistic. Berlin: Walter de Gruyter, 2004.

FOUCAULT, M. Histoire de la sexualité 3: le souci de soi. Paris: Éditions Gallimard, 1984. 
GALLI, M. “Creating religious identities': Paideia e religione nella Seconda Sofistica”. In: GOLDHILL, S. (ed.) Being Greek under Rome: Cultural identity, the Second Sophistic and the development of Empire. Cambridge: Cambridge University Press, 2001.

GLEASON, M. W. Making men: Sophists and self-presentation in ancient Rome. Princeton: Princeton University Press, 2008.

GOLDHILL, S. "Setting an agenda: Everything is Greece to the wise”. In: GOLDHILL, S. (ed.) Being Greek under Rome: Cultural identity, the Second Sophistic and the development of Empire. Cambridge: Cambridge University Press, 2001.

GRAHAM, D. W. (ed.) The texts of the early Greek philosophers: The complete fragments and selected testimony of the major presocratics. Part II. Cambridge: Cambridge University Press, 2010.

JONES, C. P. "Multiple identities in the age of the Second Sophistic". In: GOLDHILL, S. (ed.) Being Greek under Rome: Cultural identity, the Second Sophistic and the development of Empire. Cambridge: Cambridge University Press, 2001.

KENNEDY, G. A. Progymnasmata: Greek textbooks of prose composition. Atlanta: Society of Biblical Literature, 2003.

KERFERD, G. B. The Sophistic movement. Cambridge: Cambridge University Press, 1981.

KÖNIG, J. Greek literature in the Roman Empire. London: Bloomsbury Academic, 2009.

LESKY, A. Geschichte der griechischen Literatur. 3a. ed. Berlin: De Gruyter Saur, 1971.

MARTINS, P. "Uma visão periegemática sobre a écfrase”. Classica - Revista Brasileira de Estudos Clássicos, v. 29, n. 2, p. 163-204, maio 2017. ISSN 2176-6436. Disponível em: <https:// revista.classica.org.br/classica/article/view/425/373>. Acesso em: 04 set. 2017.

PERNOT, L. La Seconde Sophistique et l'antiquité tardive. Classica, v. 19, n. 1, pp. 30-44. Belo Horizonte, 2006.

RAWSON, E. "Roman rulers and the philosophic advisor". In: GRIFFIN, M. T., BARNES, J. Philosophia togata: Essays on philosophy and Roman society. Oxford: Oxford University Press, 1989.

SCHMITZ, T. Bildung und Macht: zur sozialen und politischen Funktion der zweiten Sophistik in der griechischen Welt der Kaiserzeit. Munich: Beck, 1997. "Narrator and audience in Philostratus' Lives of the Sophists". In: BOWIE, E. L., ELSNER, J. (ed.) Philostratus. Cambridge: Cambridge University Press, 2009.

SIDEBOTTOM, H. "Philostratus and the symbolic roles of the sophist and philospher". In: BOWIE, E. L., ELSNER, J. (ed.) Philostratus. Cambridge: Cambridge University Press, 2009.

SILVA, M. A. de O. “A Segunda Sofística”. Mimesis, v. 29, n. 2, pp. 151-167. Bauru, 2008. 
SIRAGO, V. A. "La Seconda Sofistica come espressione culturale della classe dirigente del II sec". Aufstieg und Niedergang der römischen Welt, v. 33, n. 1, pp. 36-78. Berlin: Walter de Gruyter, 1989.

SWAIN, S., EDWARDS, M. Approaching late antiquity: The transformation from early to late Empire. Oxford: Oxford University Press, 2006.

VEYNE, P. "L'identité grecque devant Rome et l'empereur". REG, v. 112, pp. 510-567, 1999.

WHITMARSH, T. Beyond the Second Sophistic: Adventures in Greek postclassicism. Berkeley: University of California Press, 2013.

. "Greece is the world': Exile and identity in the Second Sophistic". In: GOLDHILL, S. (ed.) Being Greek under Rome: Cultural identity, the Second Sophistic and the development of Empire. Cambridge: Cambridge University Press, 2001.

Greek literature and the Roman Empire: The politics of imitation. Oxford:

Oxford University Press, 2001. . The Second Sophistic. Oxford: Oxford University Press, 2005.

WILAMOWITZ-MÖLLENDORFF, U. von. "Asianismus und atticismus Lesefrüchte". Hermes, v. 35, n. 3, pp. 533-566, 1900.

WINTERBOTTOM, M. "Declamation and philosophy". Classica, v. 19, n. 1, pp. 74-82. Belo Horizonte, 2006. 